\title{
Anna Vannucii Receives Emerging Scholar Best Article Award, 2020
}

\author{
Roger J. R. Levesque ${ }^{1}$
}

Received: 6 October 2020 / Accepted: 6 October 2020 / Published online: 12 October 2020

(c) Springer Science+Business Media, LLC, part of Springer Nature 2020

The editors of the Journal of Youth and Adolescence are very pleased to announce the 2020 recipient of its Emerging Scholar Best Article Award. This award goes to the article's lead author, who must be an "emerging scholar" (i.e., an untenured researcher, such as a graduate student, postdoctoral scholar, research scientist, or assistant professor) at the time their manuscript was accepted. The recipient of the award is selected by editorial board members who evaluate a volume's manuscripts on the basis of their innovative and substantive contributions to the empirical understanding of adolescence. In addition to receiving the recognition from colleagues, the winner receives a financial award generously provided by Springer, the journal's publisher.

The 2020 winner is Anna Vannucci, for her article entitled "Social Media Use Subgroups Differentially Predict Psychosocial Well-Being During Early Adolescence". Anna Vannucci is a doctoral student in the Department of Psychology as Columbia University. At Columbia, she is a member of the Developmental Affective Neuroscience Lab, directed by Professor Nim Tottenham. She is interested in understanding how neural and emotional development processes link early life experiences to risk and resilience for psychopathology across childhood and adolescence. She also seeks to examine how the interplay between early life experiences and neural development influences daily emotional processes in the natural environment. Her co-author was Christine McCauley Ohannessian who, as of the writing of this editorial announcement, is the incoming Department Chair/Professor in the Department of Family and Child Sciences at Florida State University.

Their longitudinal study examined how social media use patterns relate to psychological and social functioning over time during early adolescence. They identified subgroups of early adolescents based on their social media use and

\footnotetext{
Roger J. R. Levesque

rlevesqu@indiana.edu

1 Indiana University, Bloomington, IN 47405, USA
}

examined whether these subgroups predicted psychosocial functioning. Adolescents $(\mathrm{N}=1205 ; 11-14$ years; $51 \%$ female; $51 \%$ white) completed surveys at baseline and a sixmonth follow-up. Three social media use subgroups emerged at baseline: high overall social media use (8\%); high Instagram/Snapchat use (53\%); and low overall social media use (39\%). The high social media use subgroup predicted higher depressive symptoms, panic disorder symptoms, delinquent behaviors, family conflict, as well as lower family and friend support, than the High-Instagram/ Snapchat and low social media use subgroups. The high Instagram/Snapchat use subgroup predicted higher delinquent behaviors and school avoidance than the low social media use subgroup, but also higher close friendship competence and friend support as compared to both the high social media use and low social media use subgroups. They concluded that social media use patterns appear to differentially predict psychosocial adjustment during early adolescence, with high social media use being the most problematic and patterns of high Instagram/Snapchat use and low social media use having distinct developmental tradeoffs.

The journal's editors view receiving the award as a considerably distinctive accomplishment. The journal publishes 12 issues per year, each typically containing about 16 manuscripts, as they have since the award was established 10 years ago (Levesque 2011). In addition, it is notable that, every year, fewer and fewer first authors are emerging scholars. Although fewer emerging scholars qualify to be considered, this shift in authorship has not reduced the competitiveness of the award. In fact, these developments actually make the process even more competitive for emerging scholars, as they have increased competition to get published in the first place (see Levesque 2017, 2018, 2019).

Vannucci and McCauley Ohannessian's (2019) article was one of several finalists that focused on mental health and well-being (Kwong et al. 2019; McDermott et al. 2019; Rose et al. 2019). Other finalists focused more on violence and delinquency (Davis et al. 2019; Garthe et al. 2019; 
Levey et al. 2019), school environments and outcomes (Binning et al. 2019; Gharaei et al. 2019; Gubbels et al. 2019; Lippert et al. 2019) or community influences (Fish et al. 2019; Raposa et al. 2019).

On behalf of the journal's editorial board, I would like to congratulate this year's recipient and her colleague. Their recognition comes at a remarkable time in the growth of our journal and field and highlight the need to consider and take seriously the intricacies of how changing environments influence adolescents' outcomes.

\section{Compliance with Ethical Standards}

Conflict of Interest The author is the Editor of the Journal of Youth and Adolescence.

Publisher's note Springer Nature remains neutral with regard to jurisdictional claims in published maps and institutional affiliations.

\section{References}

Binning, R. K., Wang, M., \& Amemiya, J. (2019). Persistence mindset among adolescents: who benefits from the message that academic struggles are normal and temporary? Journal of Youth Adolescence, 48, 269-286.

Davis, J. P., Ports, K. A., Basile, K. C., et al. (2019). Understanding the buffering effects of protective factors on the relationship between adverse childhood experiences and teen dating violence perpetration. Journal of Youth Adolescence, 48, 2343-2359.

Fish, J. N., Moody, R. L., Grossman, A. H., et al. (2019). LGBTQ youth-serving community-based organizations: who participates and what difference does it make? Journal of Youth Adolescence, $48,2418-2431$.

Garthe, R. C., Sullivan, T. N., \& Gorman-Smith, D. (2019). The family context and adolescent dating violence: a latent class analysis of family relationships and parenting behaviors. Journal of Youth Adolescence, 48, 1418-1432.
Gharaei, N., Thijs, J., \& Verkuyten, M. (2019). Ethnic identity in diverse schools: preadolescents' private regard and introjection in relation to classroom norms and composition. Journal of Youth Adolescence, 48, 132-144.

Gubbels, J., van der Put, C. E., \& Assink, M. (2019). Risk factors for school absenteeism and dropout: a meta-analytic review. Journal of Youth Adolescence, 48, 1637-1667.

Kwong, A. S. F., Manley, D., Timpson, N. J., et al. (2019). Identifying critical points of trajectories of depressive symptoms from childhood to young adulthood. Journal of Youth Adolescence, 48 , 815-827.

Levesque, R. J. R. (2011). Emerging scholar best article award, 2011. Journal of Youth and Adolescence, 40, 1565-1567.

Levesque, R. J. R. (2017). Emerging scholar best article award, 2017. Journal of Youth and Adolescence, 46, 2500-2501.

Levesque, R. J. R. (2018). Emerging scholar best article award, 2018. Journal of Youth and Adolescence, 47, 2637-2638.

Levesque, R. J. R. (2019). Emerging scholar best article award, 2019. Journal of Youth and Adolescence, 48, 2331-2332.

Levey, E. K. V., Garandeau, C. F., Meeus, W., et al. (2019). The longitudinal role of self-concept clarity and best friend delinquency in adolescent delinquent behavior. Journal of Youth Adolescence, 48, 1068-1081.

Lippert, A. M., Corsi, D. J., \& Venechuk, G. E. (2019). Schools Influence adolescent e-cigarette use, but when? examining the interdependent association between school context and teen vaping over time. Journal of Youth Adolescence, 48, 1899-1911.

McDermott, E. R., Umaña-Taylor, A. J., \& Zeiders, K. H. (2019). Profiles of coping with ethnic-racial discrimination and latina/o adolescents' adjustment. Journal of Youth Adolescence, 48, 908-923.

Raposa, E. B., Rhodes, J., Stams, G. J. J. M., et al. (2019). The effects of youth mentoring programs: a meta-analysis of outcome studies. Journal of Youth Adolescence, 48, 423-443.

Rose, T., McDonald, A., Von Mach, T., et al. (2019). Patterns of social connectedness and psychosocial wellbeing among African American and Caribbean Black adolescents. Journal of Youth Adolescence, 48, 2271-2291.

Vannucci, A., \& McCauley Ohannessian, C. (2019). Social media use subgroups differentially predict psychosocial well-being during early adolescence. Journal of Youth Adolescence, 48, $1469-1493$ 